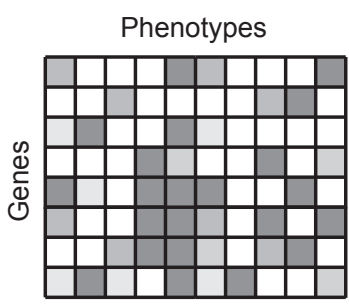

Membership of the m-th gene in the $c_{1}$ latent components

\section{Gene latent}

matrix

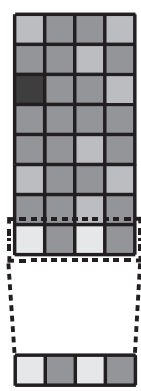

$x$

Latent component interaction matrix

Phenotype latent matrix

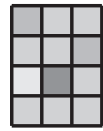

$\mathrm{X}$
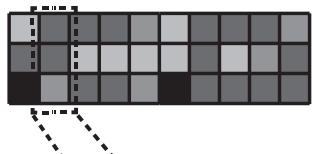

Membership of the 2 phenotype in the $\mathrm{c}_{2}$ latent components 